\title{
An inventory model for deteriorating items under time varying demand condition.
}

\author{
Srichandan Mishra ${ }^{1}$, S.P. Mishra ${ }^{2}$, N.Mishra ${ }^{3}$, J.Panda ${ }^{4}$ \\ ${ }^{1}$ Dept. of Mathematics, Govt. Science College, Malkangiri,Odisha, India. \\ Email : srichandan.mishra@gmail.com \\ ${ }^{2}$ Swarnamayee Nagar, Berhampur, Odisha, India. \\ Email : spmishrais@gmail.com \\ ${ }^{3}$ Dept. of MBA , Berhampur University, Berhampur,Odisha, India. \\ Email : nmishrabu @gmail.com \\ ${ }^{4}$ Dept. of Commerce, Berhampur University, Berhampur,Odisha, India. \\ Email : jpandabu@gmail.com
}

\begin{abstract}
In this paper we discuss the development of an inventory model for deteriorating items which investigates an instantaneous replenishment model for the items under cost minimization. A time varying type of demand rate with infinite time horizon, exponential deterioration and with shortage in considered. The result is illustrated with numerical example.
\end{abstract}

\section{Keywords}

Time varying Demand, Optimal control, Inventory system

\section{SUBJECT CLASSIFICATION}

AMS Classification No. 90B05

\section{Council for Innovative Research}

Peer Review Research Publishing System

\section{Journal: International Journal of Management \& Information Technology}

Vol. 8, No. 1

editor@cirworld.com

www.cirworld.com, member.cirworld.com 


\section{INTRODUCTION}

In inventory problems deterioration is defined as damage, spoilage, decay, obsolescence, evaporation, pilferage etc. that result in decrease of usefulness of the original one. It is reasonable to note that a product may be understood to have a lifetime which ends when utility reaches zero. The decrease or loss of utility due to decay is usually a function of the on-hand inventory. For items such as steel, hardware, glassware and toys, the rate of deterioration is so low that there is little need for considering deterioration in the determination of the economic lot size. But some items such as blood, fish, strawberry, alcohol, gasoline, radioactive chemical, medicine and food grains (i.e., paddy, wheat, potato, onion etc.) deteriorate remarkably overtime.

Whitin[17] considered an inventory model for fashion goods deteriorating at the end of a prescribed storage period. Ghare and Scharder [6] developed an EOQ model with an exponential decay and a deterministic demand. Wee[16] developed EOQ models to allow deterioration and an exponential demand pattern. Emmone[5] established a replenishment model for radioactive nuclide generators. The assumption of the constant deterioration rate was relaxed by Covert and Philip[3], who used a two-parameter Weibull distribution to represent the distribution of time to deterioration. This model was further generalized by Philip[11] by taking three-parameter Weibull distribution for deterioration.

Variation in the demand rate plays an important role in the inventory management. Therefore, decisions of inventory are to be made because of the present and future demands. Demand may be constant, time-varying, stockdependent, price-dependent etc. The constant demand is valid, only when the phase of the product life cycle is matured and also for finite periods of time. Wagner and Whitin [15] discussed the discrete case of the dynamic version of EOQ. EOQ models for deteriorating items with trended demands were considered by Bahari-Kashani [1], Goswami and Chaudhuri[7]. R.P.Tripathi[13] developed a model under time-varying demand rate and holding cost.

In the present competitive market, the effect if marketing policies and conditions such as the price variations and advertisement of an item changes its selling rate amongst the public. In selecting of an item for use, the selling price of an item is one of the decisive factors to the customers. It is commonly seen that lesser selling price causes increases in the selling rate whereas higher selling price has the reverse effect. Hence, the selling rate of an item is dependent on the selling price of that item. This selling rate function must be a decreasing function with respect to the selling price. Incorporating the price variations, recently several researchers i.e. Urban [14], Ladany and Sternleib[9], Subramanyam amd kumaraswamy[12], Goyal and Gunasekaran[8], Bhunia and Maiti[2], Luo[10], and Das et.al [4] developed their models for deteriorating and non-deteriorating items.

In the present chapter, an economic order quantity model is developed for exponential deteriorating items for time varying demand rate. Here the backlogging rate is assumed to be variable and dependent on the waiting time for the next replenishment. The time horizon is classified into two intervals. In the $1^{\text {st }}$ interval the given stock is decreased to zero level due to the combined effect of amelioration, deterioration and demand. In the next interval the shortages are allowed up to the time where some of the shortages are backlogged and rest are lost.

\section{ASSUMPTIONS AND NOTATIONS}

Following assumptions are made for the proposed model:

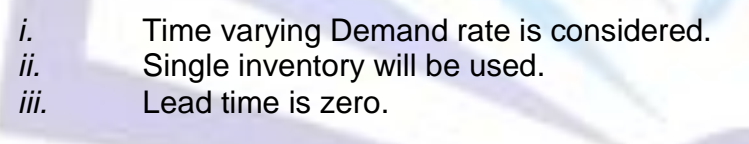

iv. Shortages are allowed and partially backlogged with the backlogging rate

backlogging parameter $\delta$ is a non-negative constant.

$v$. Replenishment rate is infinite but size is finite.

vi. Time horizon is finite.

vii. There is no repair of deteriorated items occurring during the cycle.

viii. Deterioration occurs when the item is effectively in stock.

Following notations are made for the given model:

$I(t)=$ On hand inventory at time $t$.

$R(t)=\lambda_{0} t^{-\beta}=$ Time varying demand rate where $\lambda_{0}>0$.and $0<\beta<1$. 
The distribution of the time to deterioration of an item follows the exponential distribution $\theta(t)$ where $\theta(t)=\left\{\begin{array}{ll}\theta e^{\theta t}, & \text { for } t>0 \\ 0 \quad, & \text { otherwise }\end{array}\right.$, where $\theta(0<\theta<1)$ is called as deterioration rate.

$I(0)=$ Inventory at time $t=0$.

$Q=$ On-hand inventory.

$T=$ Duration of a cycle.

$p_{c}=$ The purchasing cost per unit item.

$d_{c}=$ The deterioration cost per unit item.

$o_{c}=$ The opportunity cost per unit item.

$h_{c}=$ The holding cost per unit item.

$b_{c}=$ The shortage cost per unit item.

\section{FORMULATION}

The aim of this model is to optimize the total cost incurred and to determine the optimal ordering level. In the interval $\left[0, t_{1}\right]$ the stock will be decreased due to the effect of deterioration and demand. At time $t_{1}$, the inventory level reaches zero and in the next interval the shortage are allowed up to time where some of the shortage are backlogged and rest are lost. Only backlogged items are replaced in the next lot.

If $I(t)$ be the on hand inventory at time $t \geq 0$, then at time $t+\Delta t$, the on hand inventory in the interval $\left[0, t_{1}\right]$ will be

$$
I(t+\Delta t)=I(t)-\theta(t) I(t) \cdot \Delta t-\lambda_{0} t^{-\beta} \cdot \Delta t
$$

Dividing by $\Delta t$ and then taking as $\Delta t \rightarrow 0$ we get

$$
\frac{d I}{d t}=-\theta e^{\theta t} I(t)-\lambda_{0} t^{-\beta} \text { for } 0 \leq t \leq t_{1} .
$$

In the end interval , $\left[t_{1}, T\right]$

$$
I(t+\Delta t)=I(t)-\frac{\lambda_{0} t^{-\beta}}{1+\delta(T-t)} . \Delta t
$$

Dividing by $\Delta t$ and then taking as $\Delta t \rightarrow 0$, we get,

$$
\frac{d I}{d t}=-\frac{\lambda_{0} t^{-\beta}}{1+\delta(T-t)}, t_{1} \leq t \leq T .
$$

Now solving equation (1) with boundary condition $I\left(t_{1}\right)=0$

$$
\text { (3) } I(t)=\frac{\lambda_{0}}{2+\theta t}\left[\frac{2}{1-\beta}\left\{t_{1}^{1-\beta}-t^{1-\beta}\right\}+\frac{\theta}{2-\beta}\left\{t_{1}^{2-\beta}-t^{2-\beta}\right\}\right] \text { for } 0 \leq t \leq t_{1} \text {. }
$$

On solving equation (2) with boundary condition $I\left(t_{1}\right)=0$ 
(4) $I(t)=\lambda_{0}\left[\frac{(1-\delta T)}{1-\beta}\left\{t_{1}^{1-\beta}-t^{1-\beta}\right\}+\frac{\delta}{2-\beta}\left\{t_{1}^{2-\beta}-t^{2-\beta}\right\}\right]$ for $t_{1} \leq t \leq T$.

Form equation (3), we obtain the initial inventory level.

$$
\text { (5) } \quad I(0)=\frac{\lambda_{0}}{2}\left[\frac{2 t_{1}^{1-\beta}}{1-\beta}+\frac{\theta}{2-\beta} t_{1}^{2-\beta}\right] \text {. }
$$

The total inventory holding during the time interval $\left[0, t_{1}\right]$ is given by,

$$
\text { (6) } I_{T}=\int_{0}^{t_{1}} I d t=\frac{\lambda_{0}}{2}\left[\frac{2 t_{1}^{2-\beta}}{2-\beta}+\frac{\theta(1-\theta)}{2(3-\beta)} t_{1}^{3-\beta}\right]
$$

From of equation (4) amount of shortage during the time interval $\left[t_{1}, T\right]$ is

$$
\begin{gathered}
\text { (7) } B_{T}=\int_{t_{1}}^{T}-I d t \\
=-\lambda_{0}\left[\left\{\frac{(1-\delta T)}{1-\beta} t_{1}^{1-\beta}+\frac{\delta}{2-\beta} t_{1}^{2-\beta}\right\} .\left\{T-t_{1}\right\}-\frac{(1-\delta T)}{(1-\beta)(2-\beta)}\left\{T^{2-\beta}-t_{1}^{2-\beta}\right\}-\frac{\delta}{(2-\beta)(3-\beta)}\left\{T^{3-\beta}-t_{1}^{3-\beta}\right\}\right]
\end{gathered}
$$

The amount of lost sell during the interval $\left[t_{1}, T\right]$ in given by,

$$
L_{T}=\int_{t_{1}}^{T} R\left[1-\frac{1}{1+\delta(T-t)}\right] d t=\lambda_{0} \delta\left[\frac{T^{2-\beta}}{(1-\beta)(2-\beta)}-\frac{T \cdot t_{1}^{1-\beta}}{1-\beta}+\frac{t_{1}^{2-\beta}}{2-\beta}\right] .
$$

The total number of deteriorated units during the inventory cycle is given by,

$$
\begin{gathered}
\text { (9) } D_{T}=\int_{0}^{t_{1}} \theta(t) I(t) d t \\
=\frac{\lambda_{0} \theta}{4}\left[\left\{\frac{2 t_{1}^{1-\beta}}{1-\beta}+\frac{\theta t_{1}^{2-\beta}}{2-\beta}\right\}\left\{2 t_{1}+\frac{t_{1}^{2}}{2}+\frac{t_{1}^{3}}{3}\right\}-\frac{4}{(1-\beta)(2-\beta)} t_{1}^{2-\beta}\right. \\
\left.-\frac{2\{\theta(1-\beta)+2-\beta\}}{(1-\beta)(2-\beta)(3-\beta)} t_{1}^{3-\beta}-\frac{\{\theta(1-\beta)+2(2-\beta)\}}{(1-\beta)(2-\beta)(4-\beta)} t_{1}^{4-\beta}-\frac{\theta}{(2-\beta)(5-\beta)} t_{1}^{5-\beta}\right]
\end{gathered}
$$

Using the above equations into consideration the different costs will be as follows.

\section{Purchasing cost per cycle}

$$
\text { (10) } \quad p_{c} I(0)=\frac{\lambda_{0} p_{c}}{2}\left[\frac{2 t_{1}^{1-\beta}}{1-\beta}+\frac{\theta}{2-\beta} t_{1}^{2-\beta}\right]
$$

\section{Holding cost per cycle}

(11) $\quad h_{c} \int_{0}^{t_{1}} I(t) d t=\frac{\lambda_{0} h_{c}}{2}\left[\frac{2 t_{1}^{2-\beta}}{2-\beta}+\frac{\theta(1-\theta)}{2(3-\beta)} t_{1}^{3-\beta}\right]$ 
3. Deterioration cost per cycle

$$
\begin{gathered}
\text { (12) } d_{c} \int_{0}^{t_{1}} \theta(t) I(t) d t \\
=\frac{\lambda_{0} \theta d_{c}}{4}\left[\left\{\frac{2 t_{1}^{1-\beta}}{1-\beta}+\frac{\theta t_{1}^{2-\beta}}{2-\beta}\right\}\left\{2 t_{1}+\frac{t_{1}^{2}}{2}+\frac{t_{1}^{3}}{3}\right\}-\frac{4}{(1-\beta)(2-\beta)} t_{1}^{2-\beta}\right. \\
\left.-\frac{2\{\theta(1-\beta)+2-\beta\}}{(1-\beta)(2-\beta)(3-\beta)} t_{1}^{3-\beta}-\frac{\{\theta(1-\beta)+2(2-\beta)\}}{(1-\beta)(2-\beta)(4-\beta)} t_{1}^{4-\beta}-\frac{\theta}{(2-\beta)(5-\beta)} t_{1}^{5-\beta}\right]
\end{gathered}
$$

\section{Shortage cost per cycle}

$$
\begin{gathered}
\text { (13) }-b_{c} \int_{t_{1}}^{T} I(t) d t \\
=-\lambda_{0} b_{c}\left[\left\{\frac{(1-\delta T)}{1-\beta} t_{1}^{1-\beta}+\frac{\delta}{2-\beta} t_{1}^{2-\beta}\right\} .\left\{T-t_{1}\right\}-\frac{(1-\delta T)}{(1-\beta)(2-\beta)}\left\{T^{2-\beta}-t_{1}^{2-\beta}\right\}-\frac{\delta}{(2-\beta)(3-\beta)}\left\{T^{3-\beta}-t_{1}^{3-\beta}\right\}\right]
\end{gathered}
$$

5. Opportunity cost due to lost sales per cycle

$$
o_{c} \int_{t_{1}}^{T} R\left[1-\frac{1}{1+\delta(T-t)}\right] d t=\lambda_{0} \delta o_{c}\left[\frac{T^{2-\beta}}{(1-\beta)(2-\beta)}-\frac{T \cdot t_{1}^{1-\beta}}{1-\beta}+\frac{t_{1}^{2-\beta}}{2-\beta}\right]
$$

The average total cost per unit time of the model will be

$$
\begin{array}{r}
\text { (15) } C\left(t_{1}\right)=\frac{1}{T}\left[\frac{\lambda_{0} p_{c}}{2}\left[\frac{2 t_{1}^{1-\beta}}{1-\beta}+\frac{\theta}{2-\beta} t_{1}^{2-\beta}\right]+\frac{\lambda_{0} h_{c}}{2}\left[\frac{2 t_{1}^{2-\beta}}{2-\beta}+\frac{\theta(1-\theta)}{2(3-\beta)} t_{1}^{3-\beta}\right]\right. \\
+\frac{\lambda_{0} \theta d_{c}}{4}\left[\left\{\frac{2 t_{1}^{1-\beta}}{1-\beta}+\frac{\theta t_{1}^{2-\beta}}{2-\beta}\right\}\left\{2 t_{1}+\frac{t_{1}^{2}}{2}+\frac{t_{1}^{3}}{3}\right\}-\frac{4}{(1-\beta)(2-\beta)} t_{1}^{2-\beta}\right. \\
\left.-\frac{2\{\theta(1-\beta)+2-\beta\}}{(1-\beta)(2-\beta)(3-\beta)} t_{1}^{3-\beta}-\frac{\{\theta(1-\beta)+2(2-\beta)\}}{(1-\beta)(2-\beta)(4-\beta)} t_{1}^{4-\beta}-\frac{\theta}{(2-\beta)(5-\beta)} t_{1}^{5-\beta}\right] \\
-\lambda_{0} b_{c}\left[\left\{\frac{(1-\delta T)}{1-\beta} t_{1}^{1-\beta}+\frac{\delta}{2-\beta} t_{1}^{2-\beta}\right\} \cdot\left\{T-t_{1}\right\}-\frac{(1-\delta T)}{(1-\beta)(2-\beta)}\left\{T^{2-\beta}-t_{1}^{2-\beta}\right\}-\frac{\delta}{(2-\beta)(3-\beta)}\left\{T^{3-\beta}-t_{1}^{3-\beta}\right\}\right] \\
\left.+\lambda_{0} \delta o_{c}\left[\frac{T^{2-\beta}}{(1-\beta)(2-\beta)}-\frac{T \cdot t_{1}^{1-\beta}}{1-\beta}+\frac{t_{1}^{2-\beta}}{2-\beta}\right]\right]
\end{array}
$$

As it is difficult to solve the problem by deriving a closed equation of the solution of equation (15), Matlab Software has been used to determine optimal $t_{1}^{*}$ and hence the optimal $I(0)$, the minimum average total cost per unit time can be determined.

\section{NUMERICAL EXAMPLE}

Following example is considered to illustrate the preceding theory. 


\section{Example}

The values of the parameters are considered as follows:

$\theta=0.2, \delta=0.1, A=0.8, T=1$ Year $, \lambda_{0}=200, \beta=0.7, a_{c}=\$ 6 /$ unit,$h_{c}=\$ 4 /$ unit $/$ year

$p_{c}=\$ 15 /$ unit,$d_{c}=\$ 9 /$ unit,$o_{c}=\$ 12 /$ unit,$b_{c}=\$ 10 /$ unit. According to equation (15), we obtain the optimal $t_{1}^{*}=0.5345$ Months. In addition, the optimal $I^{*}(0)=263.425$ units. Moreover, from equation (3.15), we have the minimum average total cost per unit time as $C^{*}=260.4 \$$.

\section{CONCLUSION}

Here we have derived an inventory model for deteriorating items. In particular deterioration is considered to be of exponential type. In this model, shortages are allowed and in the shortage period the backlogging rate is variable which depends on the length of the waiting time for the next replenishment. An optimal replenishment policy is derived with minimization of average total cost under the influence of time varying demand. The result is illustrated through numerical example.

\section{REFERENCES}

[1] Bahari - Kashani, H.: "Replenishment schedule for deteriorating items with time-proportional demand", Journal of the Operational Research Society, Vol. 40,1989, pp. 75-81.

[2] Bhunia, A.K. and Maiti, M.: An inventory model for decaying items with selling price, frequency of advertisement and linearly time-dependent demand with shortages, IAPQR Transactions, 22, 41-49.

[3] Covert, R. B.; Philip, G. S.: "An EOQ model with Weibull distributed deterioration", AIEEE Transactions, Vol. 5,1973, pp. 323-326.

[4] Das, K, Bhunia, A.K. and Maiti, M.: An inventory model for deteriorating items with shortages and selling price-dependent demand, IAPQR Transactions., 24, 65-72.

[5] Emmons, H.:"A replenishment model for radioactive nuclide generators", Management Science, Vol. 14 ,1968, 263-273.

[6] Ghare P.M. and Scharder G.P.: "A model for exponentially decaying inventory", J. Ind. Eng., 14 (1963), 238243.

[7] Goswami, A.; Chaudhuri, K. S.: "An EOQ model for deteriorating items with shortages and a linear trend in demand", Journal of the Operational Research Society, Vol. 42,1991, pp. 1105-1110.

[8] Goyal, S.K. and Gunasekaran, A.: An integrated production-inventory-marketing model for deteriorating items, Computers Ind. Engg., 28, 41-49.

[9] Ladany, S. and Sternleib A.: The intersection of economic ordering quantities and marketing policies, AllE Transations., 6, 35-40.

[10] Luo, W.: An integrated inventory system for perishable goods with backordering, Computers Ind. Engg., 34, 685-693.

[11] Philip, G. C.: "A generalized EOQ model for items with Weibull distribution deterioration", AllE Transaction, Vol. 6,1974, pp. 159-162.

[12] Subramanyam, S. and Kumaraswamy, S.: EOQ formula under varying marketing policies and conditions, AlIE Transactions., 13, 312-314.

[13] Tripathi, R.P..: Inventory model with different demand rate and different holding cost, IJIEC, Volume 4, 2013, 437-446.

[14] Urban, T. L.: Deterministic inventory models incorporating marketing decisions, Computers \& Ind. Engg., 22, 85-93.

[15] Wagner, H.M.; Whitin T.M.:"Dynamic version of the economic lot size model”, Management Science, Vol. $5(1), 1958,89-96$.

[16] Wee H.M.: "A deterministic lot-size inventory model for deteriorating items with shortages on a declining market", Comp. Ops. Res., 22 (1995), 553-558.

[17] Whitin T.M.:“"Theory of inventory management”, Princeton University Press, Princeton, NJ (1957), 62-72. 